\title{
Effects of melting temperature on cerium oxidation state and crystallization on catalytic properties in cerium phosphate glasses
}

\author{
Ju-Hyeong KIM and Bong-Ki RYU ${ }^{\dagger}$ \\ School of Materials Science and Engineering, Pusan National University, Busan 609-735, Korea
}

\begin{abstract}
The effect of the melting temperature on the cerium oxidation state and crystallization of cerium phosphate glasses with a molar composition $30 \mathrm{CeO}_{2}-70 \mathrm{P}_{2} \mathrm{O}_{5}$ was investigated. $\mathrm{Ce}^{3+}$ and $\mathrm{Ce}^{4+}$ ion concentration changes in the glass attributable to the melting temperature were investigated by $\mathrm{X}$-ray photoelectron spectroscopy analysis. The crystallization kinetics of the glasses and the activation energy for crystallization were evaluated under non-isothermal conditions using differential thermal analysis (DTA) performed at different heating rates. Each DTA curve exhibited one exothermic peak associated with the crystallization of the glass. The crystalline phase was identified as $\mathrm{CePO}_{4}$ via X-ray diffractometry analysis. The Kissinger and Marotta methods were used to calculate the local activation energies for the glass samples. The amount of precipitated $\mathrm{CePO}_{4}$ with heating at $890 \mathrm{~K}$ increased as the melting temperature (or $\mathrm{Ce}^{3+}$ ) increased. The catalytic properties were studied by thermogravimetric analysis, which showed that a greater amount of precipitated $\mathrm{CePO}_{4}$ led to poorer catalytic properties of the glass.
\end{abstract}

(C2017 The Ceramic Society of Japan. All rights reserved.

Key-words : Melting temperature, Ce oxidation state, Crystallization, Catalytic properties

[Received October 31, 2016; Accepted December 17, 2016]

\section{Introduction}

Cerium has a different electronic structure from common metals, as the unfilled $4 f$ orbitals are shielded from interactions with the surrounding environment by a full octet of electrons in the $5 s^{2} p^{6}$ outer shell. Owing to this electronic structure, cerium oxide has been studied for its reduction behavior and nonstoichiometric $^{1), 2)}$ and metal-ceria interactions. ${ }^{3), 4)}$ In addition to these studies, cerium has catalytic properties in glasses. The catalytic properties of glasses containing $\mathrm{CeO}_{2}$ have been studied for the self-cleaning of household ovens ${ }^{5), 6)}$ and catalyzed diesel particulate fillers. ${ }^{7), 8)}$

To improve the catalytic properties of glass, the solubility of $\mathrm{CeO}_{2}$ having catalytic properties must be increased, and the glass must be homogeneous and without phase separation. The solubility of rare-earth ions in glass varies greatly depending on the type of glass. ${ }^{9-11)}$ Rare-earth ions have a high field strength and thus tend to form clusters. ${ }^{9), 10)}$ The solubility of rare-earth ions in pure silicate glass is less than $1 \mathrm{~mol} \%$, but phosphate-based glass is capable of dissolving large quantities of rare-earth ions because it suppresses the formation of clusters. ${ }^{11)}$ Thus, phosphate-based glasses are good candidates as hosts for catalytic applications.

The catalytic properties of the catalytic material decrease when $\mathrm{CePO}_{4}$ precipitates owing to the inhibition of the redox reaction between $\mathrm{Ce}^{3+}$ and $\mathrm{Ce}^{4+} .{ }^{12)-14)}$ Studies have investigated the decrease in the catalytic properties when $\mathrm{CePO}_{4}$ is precipitated. ${ }^{15)}$ However, few studies have been performed for preventing $\mathrm{CePO}_{4}$ precipitation to improve the catalytic performance.

The concentration of $\mathrm{Ce}^{3+}$ and $\mathrm{Ce}^{4+}$ ions depends on the melting temperature, time, and atmosphere. ${ }^{16)-18)}$ In this work, we focus on the crystallization kinetics of $\mathrm{CeO}_{2}-\mathrm{P}_{2} \mathrm{O}_{5}$ glass by varying the melting temperature to change the concentration of $\mathrm{Ce}^{3+}$ and $\mathrm{Ce}^{4+}$ ions for reducing the precipitation of $\mathrm{CePO}_{4}$.

Corresponding author: B.-K. Ryu; E-mail: bkryu@pusan.ac.kr

\section{Experimental procedure}

\subsection{Glass preparation}

A well-mixed batch $(\sim 50 \mathrm{~g})$ with a molar composition of $30 \mathrm{CeO}_{2}-70 \mathrm{P}_{2} \mathrm{O}_{5}$ was prepared by mixing analytical reagent grades of $\mathrm{CeO}_{2}$ and $\mathrm{NH}_{4} \mathrm{H}_{2} \mathrm{PO}_{4}$. Alumina crucibles containing the batch were heated at $600^{\circ} \mathrm{C}$ for $\sim 2 \mathrm{~h}$ to evaporate the water and ammonia in the batch and minimize the tendency of subsequent phosphate loss and then taken to another electric furnace preheated from 1,300 to $1,500^{\circ} \mathrm{C}$. The batch was held at the temperature for $1 \mathrm{~h}$ in air. The molten glass was quenched onto a cold stainless-steel plate. The obtained glasses were not annealed. The glasses were ground and crushed with a $44-\mu \mathrm{m}$ mesh and kept in a vacuum desiccator to avoid moisture attack.

\subsection{Measurements and analysis}

The change in the concentration of the $\mathrm{Ce}^{4+}$ and $\mathrm{Ce}^{3+}$ ions caused by the melting temperature was analyzed by X-ray photoelectron spectroscopy (XPS). The XPS spectrum was recorded using an ESCALAB 250 XPS system and a Theta Probe XPS system with monochromatic Al K $\alpha$ (hv $=1,486.6$ $\mathrm{eV}$ ) radiation. An analysis area $400 \mu \mathrm{m}$ in diameter was used and was calibrated with reference to $\mathrm{C} 1 s(284.6 \mathrm{eV})$.

The crystallization kinetics of the glasses were investigated by non-isothermal differential thermal analysis (DTA). The DTA measurements were performed using $\sim 30 \mathrm{mg}$ of the heat-treated glass powders in an air atmosphere with heating to $800^{\circ} \mathrm{C}$ at rates of $5,10,15$, and $20^{\circ} \mathrm{C} / \mathrm{min}$. Model DTG-60H (Shimadzu) and an alumina pan were used. The DTA results were analyzed to determine the crystallization mode and the activation-energy values for the crystallization of each sample using the Kissinger ${ }^{19)}$ and Marotta methods. ${ }^{20)}$ The slope of each graph was determined using the least-squares method. To identify the crystalline phases formed during the DTA heat treatment, X-ray diffraction (XRD, Rigaku-Ultima IV) were performed.

To study the effect of precipitated $\mathrm{CePO}_{4}$ on catalytic proper- 
ties, we investigated the temperature at which the fatty acid started to oxidize to $\mathrm{CO}_{2}$ and the temperature at which oxidation ended. The oxidation of the fatty acid was examined by measuring the weight loss of the sample using thermogravimetric analysis (TGA, Q600SDT, TA Instruments).

The TGA measurements were performed using $0.02 \pm 0.005$ $\mathrm{mg}$ of the glass powders and $0.02 \pm 0.005 \mathrm{mg}$ of stearic acid in an atmosphere of $\mathrm{N}_{2}$ gas, with heating to $400^{\circ} \mathrm{C}$ at rates of $10^{\circ} \mathrm{C} / \mathrm{min}$.

\section{Results and discussion}

\subsection{Effect of melting conditions on cerium oxida- tion state}

The Ce $3 d$ XPS spectra of $30 \mathrm{CeO}_{2}-70 \mathrm{P}_{2} \mathrm{O}_{5}$ obtained under different melting conditions are presented in Fig. 1. We followed the work of Eric et al. ${ }^{21)}$ for distinguishing the $\mathrm{Ce}^{3+}$ peaks from the $\mathrm{Ce}^{4+}$ peaks. $\mathrm{Ce}^{3+}$ peaks appeared at $\mathrm{v}^{0}(880.9 \mathrm{eV}), \mathrm{v}^{\prime}(885.2$ $\mathrm{eV}), \mathrm{u}^{0}(899.1 \mathrm{eV})$, and $\mathrm{u}^{\prime}(903.4 \mathrm{eV})$, and $\mathrm{Ce}^{4+}$ peaks appeared at $\mathrm{v}(882.7 \mathrm{eV}), \mathrm{v}^{\prime \prime}(888.5 \mathrm{eV}), \mathrm{v}^{\prime \prime \prime}(893.3 \mathrm{eV}), \mathrm{u}(901.3 \mathrm{eV}), \mathrm{u}^{\prime \prime}$ $(907.3 \mathrm{eV})$, and $\mathrm{u}^{\prime \prime \prime}(916.9 \mathrm{eV}) .^{21)}$ The $\mathrm{u}^{\prime \prime \prime}$ peak area shown in Fig. 1 that hardly overlaps with other peaks was reduced, and it
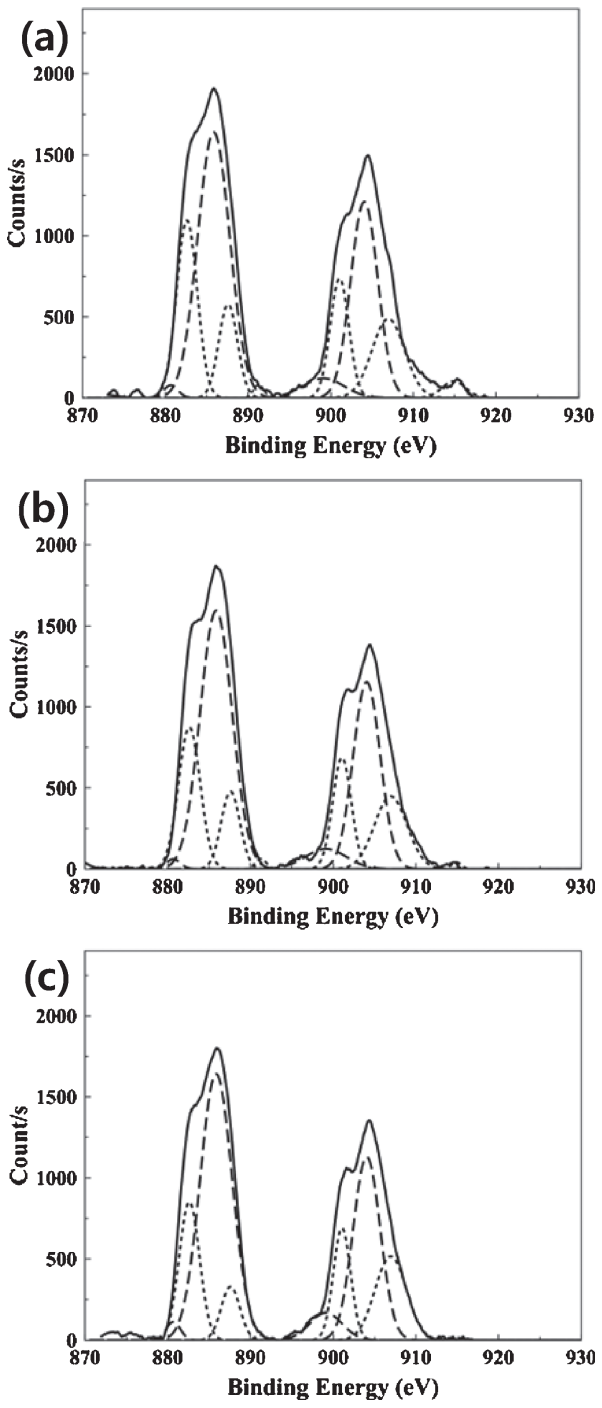

Fig. 1. Ce $3 d$ core level peak for the glass melting condition curve fitted with eight individual peaks corresponding to contributions from $\mathrm{Ce}^{3+}$ and $\mathrm{Ce}^{4+}$ ions. [(a): $1,300^{\circ} \mathrm{C}, 1 \mathrm{~h}$ melting; (b): $1,400^{\circ} \mathrm{C}, 1 \mathrm{~h}$ melting; (c): $1,500^{\circ} \mathrm{C}, 1 \mathrm{~h}$ melting], [ $\cdots$ line: $\mathrm{Ce} 4+,--$ line: $\left.\mathrm{Ce} 3+\right]$. can be qualitatively confirmed that the concentration of $\mathrm{Ce}^{3+}$ ions decreased as the melting temperature decreased. The concentrations of $\mathrm{Ce}^{3+}$ and $\mathrm{Ce}^{4+}$ ions were calculated using the Gauss method within an error of $\pm 0.3 \mathrm{eV}$ from each peak in the Ce $3 d$ spectra and are presented in the Table 1.

Figure 1 shows the equilibrium $\mathrm{Ce}^{3+}$ and $\mathrm{Ce}^{4+}$ ions. The equilibrium state of the Ce ions was affected by the melting temperature. From a theoretical viewpoint, the sign of the standard enthalpy of the $\mathrm{Ce}_{2} \mathrm{O}_{3}-\mathrm{CeO}_{2}$ oxidation reaction in the Ellingham diagram is positive $\left(\Delta H^{0}<0\right)$. Therefore, this oxidation reaction is exothermic, and the slope of the free energy line with respect to the temperature is given as follows:

$$
\Delta G^{0}=\Delta H^{0}-T \Delta S^{0}
$$

The oxidation-reduction of the oxide melt is expressed as follows:

$$
4 \mathrm{Ce}^{3+} \text { (melt) }+\mathrm{O}_{2} \text { (melt) } \leftrightarrow 4 \mathrm{Ce}^{3+} \text { (melt) }+2 \mathrm{O}^{2-} \text { (melt) }
$$

The activity of the oxide ions of the liquid phase in a restricted temperature range hardly changes, ${ }^{22)}$ it is constant depending on the chemical composition. Thus, Eq. (2) is rewritten as follows:

$$
4 \log \left(\mathrm{Ce}^{4+} / \mathrm{Ce}^{3+}\right)=\log K+\text { constant }
$$

According to the Van't Hoff equation,

$$
\log K=-\Delta H /(4.575 \mathrm{~T})+\text { constant }
$$

Combining Eqs. (3) and (4) yields

$$
4 \log \left(\mathrm{Ce}^{4+} / \mathrm{Ce}^{3+}\right)=-\Delta H /(4.575 \mathrm{~T})+\text { constant }
$$

In Eq. (5), $\Delta H$ is a negative value; i.e., the oxidation state of the $\mathrm{Ce}$ ions shifts toward the reduced species as the temperature increases.

\subsection{Thermal and structural characterization}

DTA curves measured at $15 \mathrm{~K} / \mathrm{min}$ in $\mathrm{N}_{2}$ for glasses obtained with different melting temperatures are shown in Fig. 2. As shown

Table 1. $\mathrm{Ce}^{3+}$ and $\mathrm{Ce}^{4+}$ ion concentrations in $\mathrm{CeO}_{2}-\mathrm{P}_{2} \mathrm{O}_{5}$ glasses for the following melting conditions

\begin{tabular}{ccc}
\hline Melting conditions & Ce (III) & Ce (IV) \\
\hline $1300^{\circ} \mathrm{C} 1 \mathrm{~h}$ & $56.4 \%$ & $43.6 \%$ \\
$1400^{\circ} \mathrm{C} 1 \mathrm{~h}$ & $60.1 \%$ & $39.9 \%$ \\
$1500^{\circ} \mathrm{C} 1 \mathrm{~h}$ & $63.4 \%$ & $36.6 \%$ \\
\hline
\end{tabular}

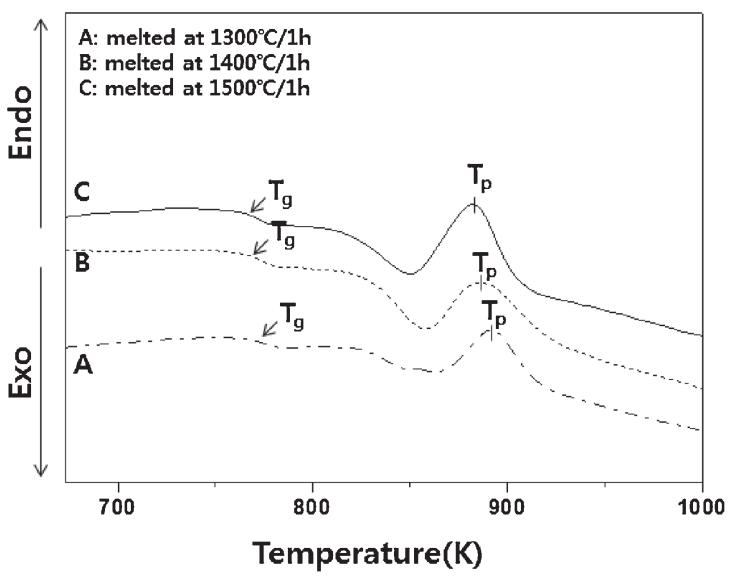

Fig. 2. DTA curves for the glass powder obtained at different melting temperatures with a heating rate of $15 \mathrm{~K} / \mathrm{min}$. 


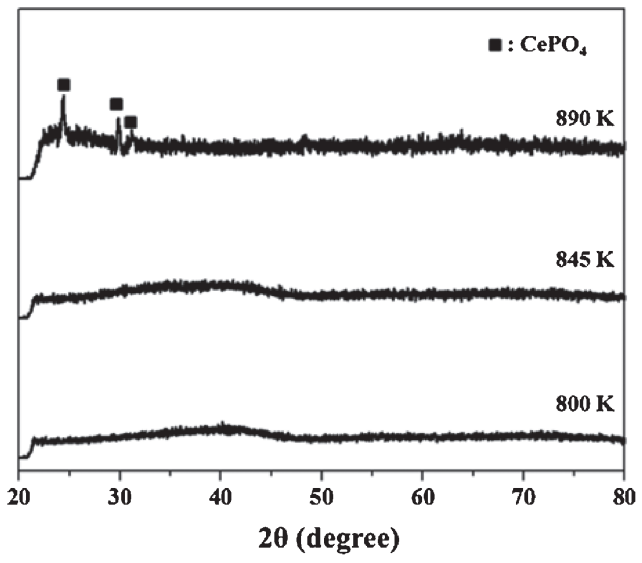

Fig. 3. XRD patterns of glass samples heat-treated at various temperatures.

in Fig. 2, each glass powder had one maximum crystallization temperature peak, $T_{\mathrm{p}}$. The software used for exothermal peak fitting was Origin Pro $8 .^{21)}$ The $T_{\mathrm{g}}$ peak decreases with increasing concentration of $\mathrm{Ce}^{3+}$. The $T_{\mathrm{g}}$ peak change is thought to be that $\mathrm{Ce}-\mathrm{O}$ bond length and coordination number are longer and larger for $\mathrm{Ce}^{3+}$ than $\mathrm{Ce}^{4+}$.9) $T$ The $T_{\mathrm{p}}$ peak for the glasses moved to lower temperatures when melting temperature increased, i.e., when concentration of $\mathrm{Ce}^{3+}$ ions in the glass increased.

$\mathrm{XRD}$ analysis was performed to confirm nucleation during DTA. Figure 3 presents the XRD patterns for the glass samples heated at $15 \mathrm{~K} / \mathrm{min}$ from room temperature to the indicated temperature and maintained at each temperature for $2 \mathrm{~h}$. These results show that no crystallization occurred for the samples heated at $800^{\circ} \mathrm{C}\left(T_{\mathrm{g}}<T<T_{\mathrm{c}}\right.$ for all DTA heating rates), whereas the samples heated at a temperature higher than $T_{\mathrm{c}}$ for $1 \mathrm{~h}$ exhibited diffraction peaks. The XRD results in Fig. 3 indicate that the exothermic peaks in the DTA curves are associated with the crystalline phase of $\mathrm{Ce}_{\mathrm{P}} \mathrm{O}_{4}$.

\subsection{Kinetic parameters of crystal growth}

The activation energy for crystallization was determined using the Kissinger and Marotta equations:

$$
\begin{aligned}
& \ln \left(\frac{\alpha}{T_{\mathrm{p}}^{2}}\right)=-\frac{E_{\mathrm{c}}}{R T_{\mathrm{p}}}+\text { constant, } \\
& \ln \alpha=-\frac{E_{\mathrm{c}}}{R T_{\mathrm{p}}}+\text { constant, }
\end{aligned}
$$

where $\alpha$ is the DTA heating rate, $E_{\mathrm{c}}$ is the activation energy, $T_{\mathrm{p}}$ is the maximum crystallization temperature, and $R$ is the gas constant.

The $\ln \left(T_{\mathrm{p}}^{2} / \mathrm{a}\right)$ vs. $1 / T_{\mathrm{p}}$ [Eq. (6)] and $\ln (\mathrm{a})$ vs. $1 / T_{\mathrm{p}}$ [Eq. (7)] plots for the glasses melted at different temperatures obtained at heating rates $(\alpha)$ of 5, 10, 15, and $20 \mathrm{~K} / \mathrm{min}$ are shown in Fig. 4. The activation energy for crystallization, $E_{\mathrm{c}}$, determined according to the slope of these straight lines is given in Table 2.

The activation energies obtained according to Eqs. (6) and (7) were 338 and $352 \mathrm{KJ} / \mathrm{mol}$, respectively, for the glass melted at the $1,300^{\circ} \mathrm{C}$ exothermic peak. The activation energies of the glass melted at $1,400^{\circ} \mathrm{C}$ were 304 and $318 \mathrm{KJ} / \mathrm{mol}$, and those of the glass melted at $1,500^{\circ} \mathrm{C}$ were 278 and $292 \mathrm{KJ} / \mathrm{mol}$. For both the Kissinger and Marotta equations, the activation energy of crystallization decreased when the melting temperature increased. These results suggest that a larger amount of $\mathrm{Ce}^{3+}$ ions yields more sites for nucleation, and the crystallization tendency increases with the increasing concentration of $\mathrm{Ce}^{3+}$ ions.
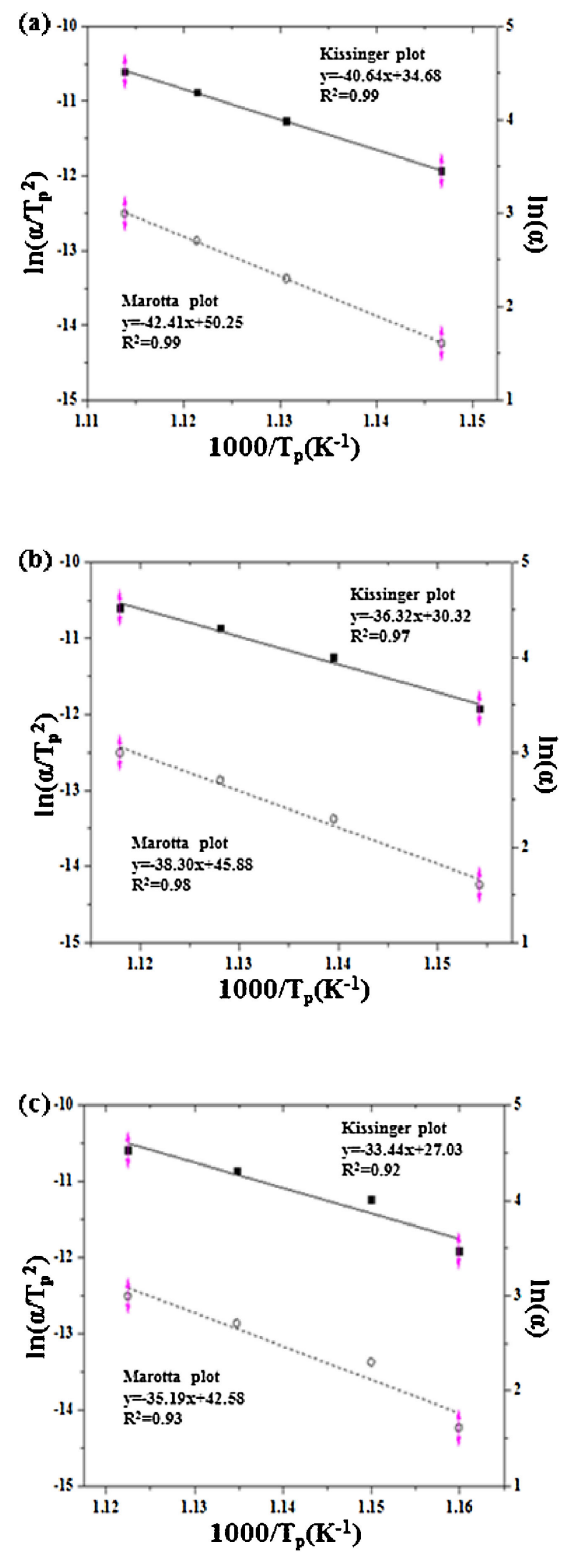

Fig. 4. Kissinger and Marotta plots for the crystallization peaks.

Table 2. Thermal properties as measured by DTA at a heating rate of $15 \mathrm{~K} / \mathrm{min}$ in a nitrogen atmophere for the crystallization peaks of glasses formed by melting at different temperatures for $1 \mathrm{~h}$ in air

\begin{tabular}{ccccccc}
\hline Sample & $\begin{array}{c}\text { Melting } \\
\text { temp. } \\
\left({ }^{\circ} \mathrm{C}\right)\end{array}$ & $\begin{array}{c}T_{\mathrm{g}} \\
(\mathrm{K})\end{array}$ & $\begin{array}{c}T_{\mathrm{c}} \\
(\mathrm{K})\end{array}$ & $\begin{array}{c}T_{\mathrm{P}} \\
(\mathrm{K})\end{array}$ & $\begin{array}{c}\text { Kissinger- } \\
\text { activation } \\
\text { energy } E_{\mathrm{c}} \\
(\mathrm{kJ} / \mathrm{mol})\end{array}$ & $\begin{array}{c}\text { Marotta- } \\
\text { activation } \\
\text { energy } E_{\mathrm{c}} \\
(\mathrm{kJ} / \mathrm{mol})\end{array}$ \\
\hline $\mathrm{A}$ & 1300 & 772 & 864 & 890 & 338 & 352 \\
$\mathrm{~B}$ & 1400 & 768 & 857 & 886 & 304 & 318 \\
$\mathrm{C}$ & 1500 & 766 & 851 & 883 & 278 & 292 \\
\hline
\end{tabular}

\subsection{Catalytic properties}

Fatty acid was loss the weight by the oxidation reaction with the converted into a gas. ${ }^{23)}$ The catalyst promotes the oxidation by reducing the oxidation temperature of the fatty acid. We compared the performance of a glass catalyst subjected to by weight loss due to oxidation.

The TGA results for stearic acid and glass samples heated at different conditions are shown in Fig. 5 and Table 3. The 


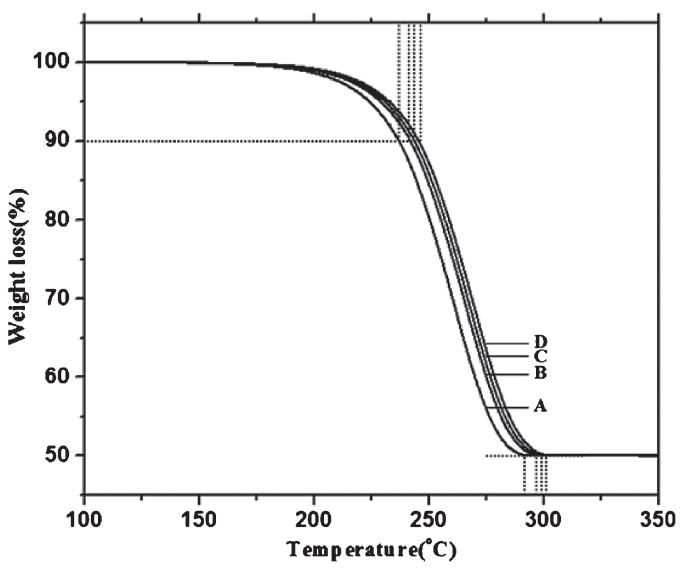

Fig. 5. TGA curves for $\mathrm{CeO}_{2}-\mathrm{P}_{2} \mathrm{O}_{5}$ glass catalysts in stearic acid mixed at a weight ratio of approximately $1: 1$.

Table 3. Weight loss of stearic acid with $\mathrm{CeO}_{2}-\mathrm{P}_{2} \mathrm{O}_{5}$ glasses formed by melting at different temperatures for $1 \mathrm{~h}$ in air and heating at diffenent conditions

\begin{tabular}{ccccc}
\hline Sample & $\begin{array}{c}\text { Melting temp. } \\
\left({ }^{\circ} \mathrm{C}\right)\end{array}$ & $\begin{array}{c}\text { Heating } \\
\text { conditions }\end{array}$ & $\begin{array}{c}\text { Start temp. } \\
\text { of weight loss } \\
\left({ }^{\circ} \mathrm{C}\right)\end{array}$ & $\begin{array}{c}\text { Finish temp. } \\
\text { of weight loss } \\
\left({ }^{\circ} \mathrm{C}\right)\end{array}$ \\
\hline A & 1300 & - & 236.7 & 289.2 \\
B & 1300 & $890 \mathrm{~K} 1 \mathrm{~h}$ & 244.3 & 296.3 \\
$\mathrm{C}$ & 1400 & $890 \mathrm{~K} 1 \mathrm{~h}$ & 246.2 & 299.8 \\
$\mathrm{D}$ & 1500 & $890 \mathrm{~K} 1 \mathrm{~h}$ & 248.6 & 304.0 \\
\hline
\end{tabular}

samples were glass frit mixed with stearic acid at a weight ratio of $1: 1$. For the glass melted at $1,300^{\circ} \mathrm{C}$ (no $\mathrm{CePO}_{4}$ precipitated), the starting decomposition temperature was $236.7^{\circ} \mathrm{C}$, and the ending decomposition temperature $289.2^{\circ} \mathrm{C}$. For the glass melted at different temperatures and heated at $890 \mathrm{~K}$ for $1 \mathrm{~h}\left(\mathrm{CePO}_{4}\right.$ precipitated), the starting decomposition temperatures were 244.3$248.6^{\circ} \mathrm{C}$, and the ending decomposition temperature $296.2-$ $304.0^{\circ} \mathrm{C}$, as shown Table 3. The temperature at which the stearic acid started to oxidize to $\mathrm{CO}_{2}$ and the temperature at which the oxidation ended increased with increasing amounts of precipitated $\mathrm{CePO}_{4}$.

The reason for the temperature change is thought to be that the redox reaction is inhibited between $\mathrm{Ce}^{3+}$ and $\mathrm{Ce}^{4+}$ when $\mathrm{CePO}_{4}$ is precipitated in cerium-based catalysts. ${ }^{12)-14)}$ Hence, as the melting temperature $\left(\mathrm{Ce}^{3+}\right)$ increases, the precipitation of $\mathrm{CePO}_{4}$ increases, and the starting temperature of the oxidation of stearic acid and the oxidation ending temperature increase.

\section{Conclusion}

We investigated the effect of the melting temperature on cerium oxidation state and the effect of the crystallization of cerium phosphate glass on the catalytic properties to further the development of cerium phosphate glass.

The effects of the melting temperature on the cerium oxidation state were studied by XPS. A $30 \mathrm{CeO}_{2}-70 \mathrm{P}_{2} \mathrm{O}_{5}$ mol \% composition that initially contained only $\mathrm{Ce}^{4+}$ ions resulted in glasses that contained both $\mathrm{Ce}^{3+}$ and $\mathrm{Ce}^{4+}$ ions and increased concentrations of $\mathrm{Ce}^{3+}$ when melted at high temperatures.

The crystallization kinetics was studied by non-isothermal
DTA and XRD. The calculated values for glasses melted at 1,300, 1,400 , and $1,500^{\circ} \mathrm{C}$ were 338,304 , and $278 \mathrm{~kJ} / \mathrm{mol}$, respectively, according to the Kissinger method and 352, 318, and $292 \mathrm{~kJ} / \mathrm{mol}$, respectively, according to the Marotta method.

The catalytic properties were studied by TGA. As the melting temperature $\left(\mathrm{Ce}^{3+}\right.$ ion concentration) increased, the amount of the precipitated $\mathrm{CePO}_{4}$ crystalline phase increased. A larger amount of precipitated $\mathrm{CePO}_{4}$ yielded a greater reduction in the catalytic properties of the glass.

Acknowledgement This research was supported by the Ministry of Trade, Industry \& Energy(MOTIE), Korea Institute for Advancement of Technology(KIAT) and Ulsan Institute For Regional Program Evaluation(IRPE) through the Encouragement Program for The Industries of Economic Cooperation Region.

\section{References}

1) A. Trovarelli, Catal. Rev., Sci. Eng., 38, 439-520 (1996).

2) G. Ranga Rao, Bull. Mater. Sci., 22, 89-94 (1999).

3) G. R. Rao, P. Fornasiero, R. D. Monte, J. Kašpar, G. Vlaic, G. Balducci, S. Meriani, G. Gubitosa, A. Cremona and M. Graziani, J. Catal., 162, 1-9 (1996).

4) P. Fornasiero, G. R. Rao, J. Kašpar, F. L. Erario and M. Graziani, J. Catal., 175, 269-279 (1998).

5) P. Palmisano, P. Faraldi, D. Fino and N. Russo, Chem. Eng. Sci., 154, 251-257 (2009).

6) P. Palmisano, S. P. Hernandez, M. Hussain, D. Fino and N. Russo, Chem. Eng. Sci., 176, 253-259 (2011).

7) W. Yuechang, Z. Zhen, J. Jinqing, L. Jian, D. Aijun and J. Guiyuan, J. Rare Earths, 32, 124-130 (2014).

8) F. E. Tuler, E. D. Banus, M. A. Zanuttini, E. E. Miro and V. G. Milt, Chem. Eng. J., 246, 287-298 (2014).

9) J. Du, L. Kokou, J. L. Rygel, Y. Chen, C. G. Pantano, R. Woodman and J. Belcher, J. Am. Ceram. Soc., 94, 2393-2401 (2011).

10) W. J. Miniscalco, J. Lightwave Technol., 9, 234-250 (1991).

11) H. Iwanaga, Materials (Basel), 3, 4080-4108 (2010).

12) C. Larese, F. Cabello Galisteo, M. Lopez Granados, R. Mariscal, J. L. G. Fierro, M. Furio and R. F. Ruiz, Appl. Catal., B, 40, 305-317 (2003).

13) C. Larese, F. C. Galisteo, M. L. Granados, R. Mariscal, J. L. G. Fierro, P. S. Lambrou and A. M. Efstathiou, Appl. Catal., B, 48, 113-123 (2004).

14) S. Y. Christou, S. Garcia-Rodriquez, J. L. G. Fierro and A. M. Efstathiou, Appl. Catal., B, 111-112, 233-245 (2012).

15) J. Y. Chung, J. H. Kim, Y. S. Kim, S. Y. Choi, I. G. Kim, H. J. Park and B. K. Ryu, J. Ceram. Soc. Japan, 123, 147-151 (2015).

16) P. Nath and B. S. Tyagi, Bull., Cent. Glass Ceram. Res. Inst, 19, 80-91 (1972).

17) O. Pinet, J. Phalippou and C. D. Nardo, J. Non-Cryst. Solids, 352, 5382-5390 (2006).

18) W. D. Johnston, J. Am. Ceram. Soc., 48, 184-190 (1965).

19) H. E. Kissinger, J. Res. Natl. Stand. (U.S.), 57, 217-221 (1956).

20) A. Marotta and A. Buri, Thermochim. Acta, 25, 155-160 (1978).

21) E. Beche, P. Charvin, D. Perarnau, S. Abanades and G. Flamant, Surf. Interface Anal., 40, 264-267 (2008).

22) G. W. Toop and C. S. Samis, Trans. Met. Soc., AIME 224, 878887 (1962).

23) B. Renard, J. Barbier, Jr., D. Duprez and S. Durecu, Appl. Catal., 55, 1-10 (2005). 